\title{
ПОЛИТИКА
}

\section{ТАНЦУРА Марина Сергеевна}

канд. полит. наук, доцент кафедры политологии Восточного института - Школь региональных и международных исследований, ДВФУ (г. Владивосток)

Электронная почта: tatuika@mail.ru

\section{САДОВНИКОВА Александра Алексеевна}

магистрантка направления «Общзя политология», Московского государственного университета им. Ломоносова (2. Москва)

Электронная почта: sandraanna482@gmail.com

\section{Исследование сетевой активности как инструмента политической мобилизации молодёжи} (на примере антикоррупционных митингов 26 марта 2017 г.)

\section{УДК 323.2}

\section{Интернет,} интернет-технологии, политическое участие, политическая активность, сетевая активность, митинг

doi: dx.doi.org/10.24866/2542-1611/2019-1/46-55

\begin{abstract}
Проблема сетевой активности молодёжи стала особенно актуальной в последние годы, когда пространство российской политики приобрело устойчивые виртуальные характеристики. Практика мобилизации молодёжи, вывод её из виртуального пространства в офлайн - достаточно новое явление для российской политики, требующее пристального внимания. В работе отражены результаты количественного и качественного анализа контента социальных сетей в период с 2.03.2017 по 15.04.2017 с помощью программы мониторинга социальных медиа «IQBuzz». Полученные данные позволили сделать выводы о некоторых особенностях российского сетевого коммуникационного пространства.
\end{abstract}

\begin{abstract}
Статья подготовлена на основе доклада на всероссийской научно-практической конференции «Азиатско-тихоокеанские исследования: социум, культура, политика», проведённой Восточным институтом - Школой региональных и международных исследований ДВФУ 6 марта 2019 г.
\end{abstract}

Для иитирования:

Танцура М.С., Садовникова А.А. Исследование сетевой активности как инструмента политической мобилизации молодёжи (на примере антикоррупционных митингов 26 марта 2017 г.)

// Известия Восточного института. 2019. № 1. С. 46-55. doi: dx.doi.org/10.24866/25421611/2019-1/46-55
Процесс развития информационно-коммуникационных технологий в XXI веке стал толчком для возрастания роли информационного пространства в целом. Активно формируется сетевое социальное пространство, открывающее новые возможности для гражданского участия, оппозиционных движений и контроля публичной политики. В результате социальные сети играют всё более значительную роль в формировании и регулировании разного рода социальных взаимодействий.

Интернет меняет отношение граждан к традиционным политическим институтам и привычным способам коммуникации. Здесь мы наблюдаем, с одной стороны, большее давление на структуры власти, а с другой - большие возможности для взаимодействия между гражданами, социальными институтами и государством. Существенно обновляется сама система обмена смыслами между субъектами политического процесса, когда в структуру политической коммуникации включается сеть Интернет как фактор, отражающий процесс медиатизации политики, перемещения её в символическое пространство CMK.

Интернет-коммуникация имеет свои особенности, «...это оптический, практически мгновенный, способ производства 
аберраций информации, который оказывает влияние на политический процесс. В отличие от устной и письменной коммуникации, которой свойственно диффузное распространение..., оптический способ передачи информации ведёт к тому, что акторы воспринимают все волны информации, множество смыслов одновременно» [4].

Исследованием места и роли информационных технологий в современном политическом процессе занимались Э. Тоффлер, Д. Белл, И. Масуда и др. [1;6;11]. Среди отечественныхучёных, изучавших коммуникативные технологии, стоит упомянуть М. Ю. Павлютенкову, А. А. Ильина и др. [2; 9].

Сетевая природа Интернета изменяет модель односторонней массовой трансляции информации от субъекта к целевым аудиториям и предоставляет широчайшие возможности горизонтальной коммуникации. Возможности индивида по реконструированию сетей и объединению в сообщества создаёт предпосылки для изменения механизмов политического неконвенционального участия. Начиная с 2011 года активность протестных групп, развивавшаяся в сети, стала проявляться в публичном пространстве и выходить за пределы виртуальных сообществ и проявляться в публичном пространстве в виде массовых митингов и шествий. Возникающие в Рунете формы самоорганизации дали начало гражданским инициативам, которые идут в тесном переплетении с политическими требованиями, такими как протест против коррупции, судебной и правоохранительной систем. Такие информационные средства, как электронная почта, Facebook, Twitter, различные чатклиенты, блоги и сервисы по обмену видеофайлами (наподобие YouTube), стали мощными инструментами как индивидуальных, так и коллективных действий. В пространстве Рунета формируется особая контркультура заметной части общества, выдвигающей все новые инициативы, которые приводят к широкомасштабным коллективным действиям.

На сегодня электронные социальные сети в нашей стране предоставляют возможность выстроить эффективную коммуникацию между группой или группами индивидов, объединённых одной целью, тем самым эффективно выполняя функции артикуляции и агрегации интересов, говоря языком Г. Алмонда. Российский политический процесс содержательно и структурно отличается от политических процессов европейских и американской демократий, однако информационная составляющая российского политического пространства идёт вперёд колоссальными темпами. Нынешняя политическая активность граждан в интернете - это, по сути, протополитическая партия, которая со временем может превратиться в реальную. За последние пять лет произошли качественные изменения в использовании социальных сетей, и сегодня, по опросам ВЦИОМ, в среде молодёжи интернет как источник информации обогнал телевидение. А, в свою очередь, именно социальные сети стали основным способом коммуникации: среди молодёжи - в группе 18-24 лет почти ежедневно пользуются социальными сетями 91\%, среди опрошенных 25-34 лет таких 69\% [3]. Эти изменения были незаметны и не учитывались аналитиками и исследователями до начала мартовских событий 2017 года.

В конце марта 2017 г. на антикоррупционные митинги по всей России вышло около 60 тысяч человек более чем в 80 городах страны. Большинство протестных акций не были согласованы с властями. Самые крупные состоялись в Москве (около 15 тысяч участников, 1030 человек задержаны) и Санкт-Петербурге (до 10 тысяч участни- 
ков, 131 задержаны) [5]. По свидетельствам очевидцев, значительное число участников составляла молодёжь.

В работе отражены результаты количественного и качественного анализа контента социальных сетей в период с 2.03.2017 по 15.04.2017, с помощью программы мониторинга социальных медиа «IQBuzz» [10].

Исследование проводилось в несколько этапов:

- проведён контент-анализа основных новостных лент;

- был сформирован словарь активной лексики;

- после введения основных словосочетаний, часть подобранных документов просматривалась вручную для выявления ошибочного определения тональности документа. При нахождении несоответствий критерии уточнялись, и цикл работы с контентом запускался заново. Всего было проведено семь циклов итераций.

Для проведения полноценного анализа события был использован следующий словарь ключевых слов: «ФБК|»фонд борьбы с коррупцией»|»расследования Навального», митинг|»антикоррупционный митинг»|»протестные, акции»|»митинг, 26 марта»|»митинг против коррупции»|»митинг по всей стране», «алексей навальный», навальный «команда навального», «дмитрий медведев», медведев, «Димон ответит», «он вам не Димон», «26 марта»».

Результатом работы является автоматизированная дифференциация массива данных по различным критериям. В силу объективных причин не представлялось возможным проанализировать весь массив информации по данному вопросу. Максимальное количество документов, которые может охватить система CM IQBUZZ - 5000 единиц, для анализа выбирались самые популярные (т.е. отбор происходил по количеству лайков и репостов»).

Первоначальной точкой анализа было распределение документов по тональности, результаты представлены на диаграмме 1. Для определения тональности мы составили словарь негативных и позитивных оценок. В данном случае негатив анализировался с помощью слов, имеющих отношение к задержаниям, увольнениям, замалчиванию факта митинга и т. д., позитив - с помощью словаря противников Навального, транслирующих отношение к заграничному финансированию, лживости персоны Навального и т.д.

Исходя из данных рис. 1, можно сделать вывод о том, что в социальных сетях преобладает негатив, т.е. в нашем случае - это поддержка митинга и негативное отношение к власти в целом. Взрыв негатива, по нашему мнению, связан в первую очередь с замалчиванием факта о митингах в СМИ, массовыми задержаниями и увольнениями людей после участия в самих акциях протеста или открытых их обсуждениях. Позитив же, в свою очередь, связан с противоречивой фигурой Навального. Смешанные и нейтральные оценки чаще всего связаны с некорректным поведением митингующих и неверием в эффективность данного способа борьбы и выражения протеста.

Следующим этапом стал анализ источников самых популярных постов, данные представлены в виде рис. 2.

Исходя из данных, приведённых на рис. 2, мы видим, что основное освещение и обсуждение антикоррупционные митинги получили в таких социальных сетях, как «твиттер» и «вконтакте». Выбор этих социальных сетей не случаен, учитывая медианный возраст митин- 


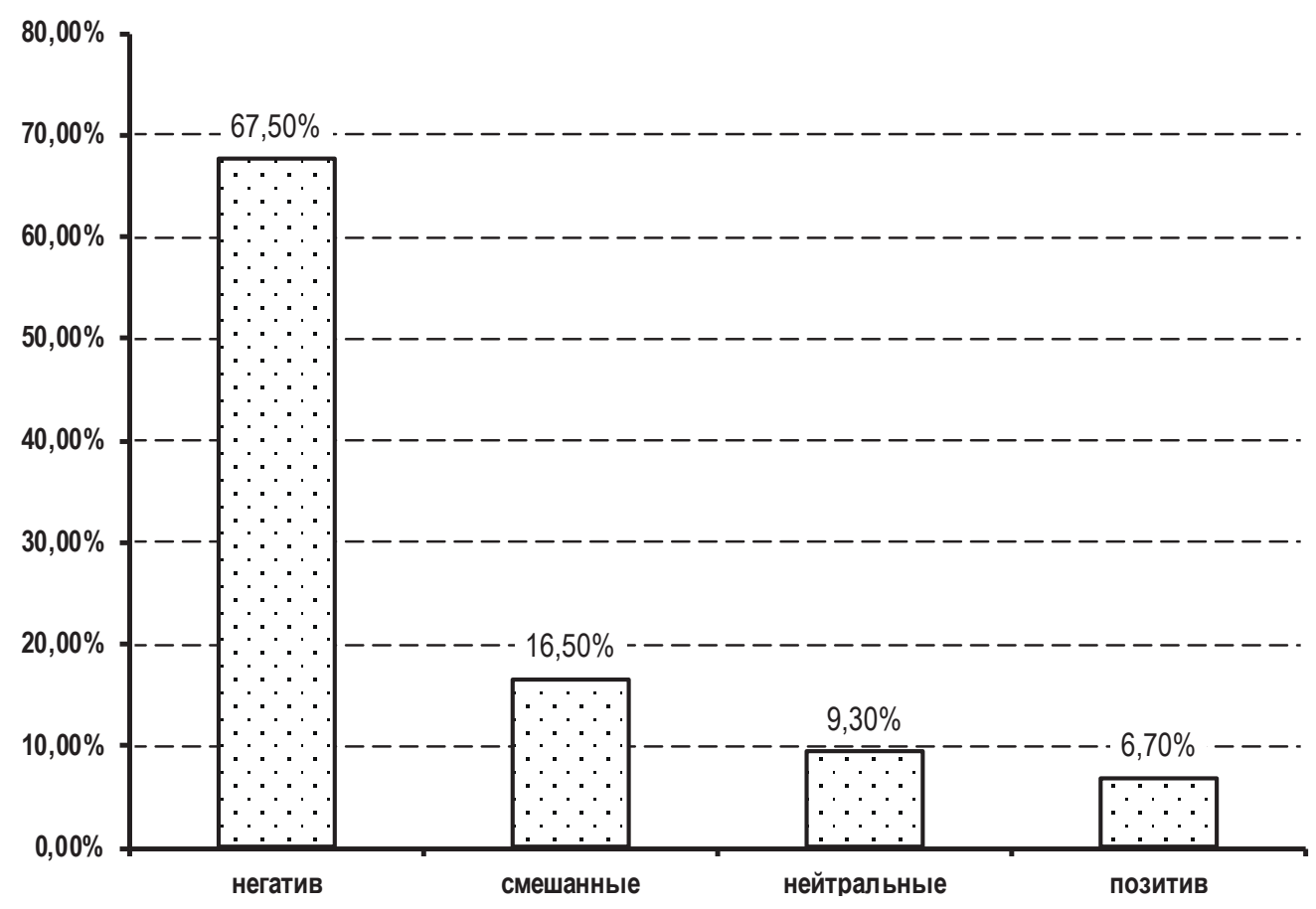

гующих и наибольший охват аудитории. Существенным минусом является то, что при анализе мы не смогли взять в расчёт видеохостинг «YouTube». Именно с фильма «он вам не Димон», выпущенного ФБК в начале марта на YouTube начинается протестное движение [7]. Данный фильм собрал около 28 миллионов просмотров, что в десятки раз больше чем любое другое расследование ФБК, это больше, чем мог собрать любой контент медиа, неподконтрольного власти.

Третий этап анализа направлен на изучение активности блогов. В данном случае мы выбрали 30 источников с наибольшим охватом аудитории (результаты представлены в табл. 1).

Исходя из данных, полученных в ходе анализа, мы можем наблюдать, что помимо личного «твиттера» людей, поддерживающих митинг и конкретно политических пабликов, здесь присутствуют ресурсы, не имеющие прямого отношения к политике, такие как «мамы детям», «хоккейная империя» и т. д.) Чем обусловлен интерес развлекательного контента к политическому, всегда занимавшему крохотную часть Рунета? Политический контент на несколько дней стал главной темой для миллионов людей, до этого едва ли знавших Навального и ФБК, все это произошло благодаря появлению большого количества так называемых «мемов», связанных с тематикой митинга. Двадцать шестого марта уточки и кроссовки вирусно распространились на весь российский интернет.

Следующим этапом анализа стал вопрос определения возраста авторов постов, посвящённых мартовскому митингу. Ему сразу же по окончании было присвоено множество публицистических штампов - «революция школьных ранцев», «школьный митинг» и т. д. Все
Puc. 1 .

Распределение тональности документов, посвящённых митингу 26.03.17. Источник: составлено автором. 


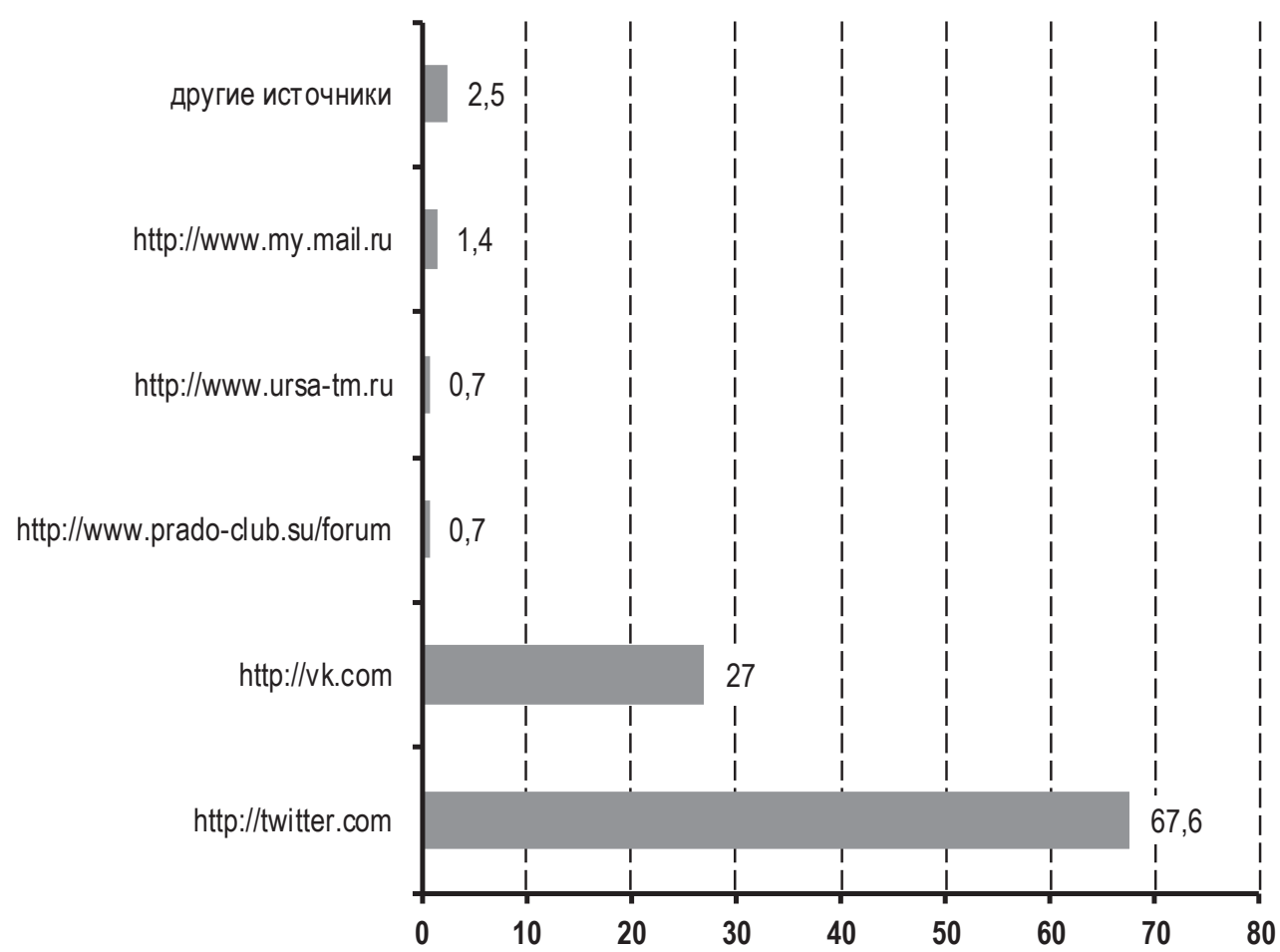

Рuc. 2.

Распределение сообщений о митинге в интернет-пространстве. Источник: составлено автором. они подчёркивали массовое участие в митингах несознательной, не имеющей избирательного права, мало разбирающейся в современной российской политике молодёжи. Эти характеристики напрямую подчёркивают факт омоложения протестного движения в России, однако доказательных исследований на момент окончания акций проведено не было. Именно для того, чтобы разобраться в правильности публицистического штампа, мы решили проанализировать возрастные категории авторов постов на тему событий 26 марта 2017 г. Отметим, что аналитическая система IQBuzz не учитывает авторов, не указавших свой возраст. Результаты анализа представлены на рис. 3.

Исходя из полученных результатов, мы видим, что доля школьников ничтожно мала по сравнению с остальными возрастными категориями, поэтому правильнее было бы говорить о том, что был это не «митинг школьников», а скорее «митинг студентов» и «недавних студентов». По заявлениям свидетелей, медианный возраст участников политических протестов заметно снизился. Эксперты и аналитики утверждают, что миллениары становятся слишком заметной группой и стратегия запугивания и давления в школах и университетах, скорее всего, обречена на провал [8]. Благодаря их активности в социальных сетях, множество людей открыло для себя существование незаконных задержаний, несправедливых судов, замалчивание нежелательных тем или откровенную ложь в эфире - уже один этот факт можно считать победой команды Навального в борьбе за молодёжь, до сих пор считающуюся полностью аполитичной. Хотя следует отметить, что большинство молодых людей-участников акций протеста, с ко- 


\begin{tabular}{|c|c|c|c|c|}
\hline № & Название блога или URL & Блогхостинг & Документов & Аудитория \\
\hline 1. & tvrain & Twitter & 2 & 2284305 \\
\hline 2. & navalny & Twitter & 3 & 1923431 \\
\hline 3. & anekdotru & Twitter & 1 & 1501243 \\
\hline 4. & EchoMskRu & Twitter & 4 & 1279103 \\
\hline 5. & RT_russian & Twitter & 1 & 887369 \\
\hline 6. & Vedomosti & Twitter & 1 & 869408 \\
\hline 7. & tjournal & Twitter & 2 & 632406 \\
\hline 8. & Novaya_gazeta & Twitter & 4 & 463380 \\
\hline 9. & Tass_agensy & Twitter & 3 & 449387 \\
\hline 10. & 1tvru_news & Twitter & 1 & 394522 \\
\hline 11. & plushev & Twitter & 4 & 357803 \\
\hline 12. & EchoMskNews & Twitter & 1 & 288030 \\
\hline 13. & rsportru & Twitter & 1 & 305056 \\
\hline 14. & varlamov & Twitter & 1 & 262929 \\
\hline 15. & khodorkovsky & Twitter & 1 & 268567 \\
\hline 16 & $\begin{array}{c}\text { Мамы детям: рукоделие, вязание, } \\
\text { шитье, развитие }\end{array}$ & VKontakte & 1 & 274940 \\
\hline 17. & Я_РУССКИЙ & VKontakte & 1 & 229392 \\
\hline 18. & gudkovd & Twitter & 1 & 248953 \\
\hline 19. & SvobodaRadio & Twitter & 1 & 248842 \\
\hline 20. & $\mathrm{Ru} \_r b c$ & Twitter & 2 & 267732 \\
\hline 21. & [ХОККЕЙ]НАЯ ИМПЕРИЯ & VKontakte & 1 & 208113 \\
\hline 22. & Alexey Navalny & VKontakte & 2 & 190464 \\
\hline 23. & ФК «Спартак-Москва»|RedWhite & VKontakte & 2 & 188342 \\
\hline 24. & DLGreez & Twitter & 1 & 344713 \\
\hline 25. & drysyaRF & Twitter & 3 & 144904 \\
\hline 26. & leonidvolkov & Twitter & 1 & 184050 \\
\hline 27. & 72.ru - Новости Тюмени & VKontakte & 1 & 141281 \\
\hline 28. & imercouri & Twitter & 2 & 153167 \\
\hline
\end{tabular}

торыми удалось пообщаться СМИ, утверждают, что они вышли не за Навального, а против Медведева.

Финальным этапом исследования стал территориальный анализ. Ни один регион не остался в стороне от обсуждения данного митинга. Мы представим несколько самых активных территорий, лидирующих в обсуждении мартовского митинга в социальных сетях.

Неизменными лидерами являются Москва и Санкт-Петербург, где проходили и митинги 2012 года (см. табл. 2) Новым в мартовских протестах-2017 стало то, что впервые за многие годы они вышли за
Табл. 1.

Частота упоминания митинга в различных социальных сетях. Источник: составлено автором. 


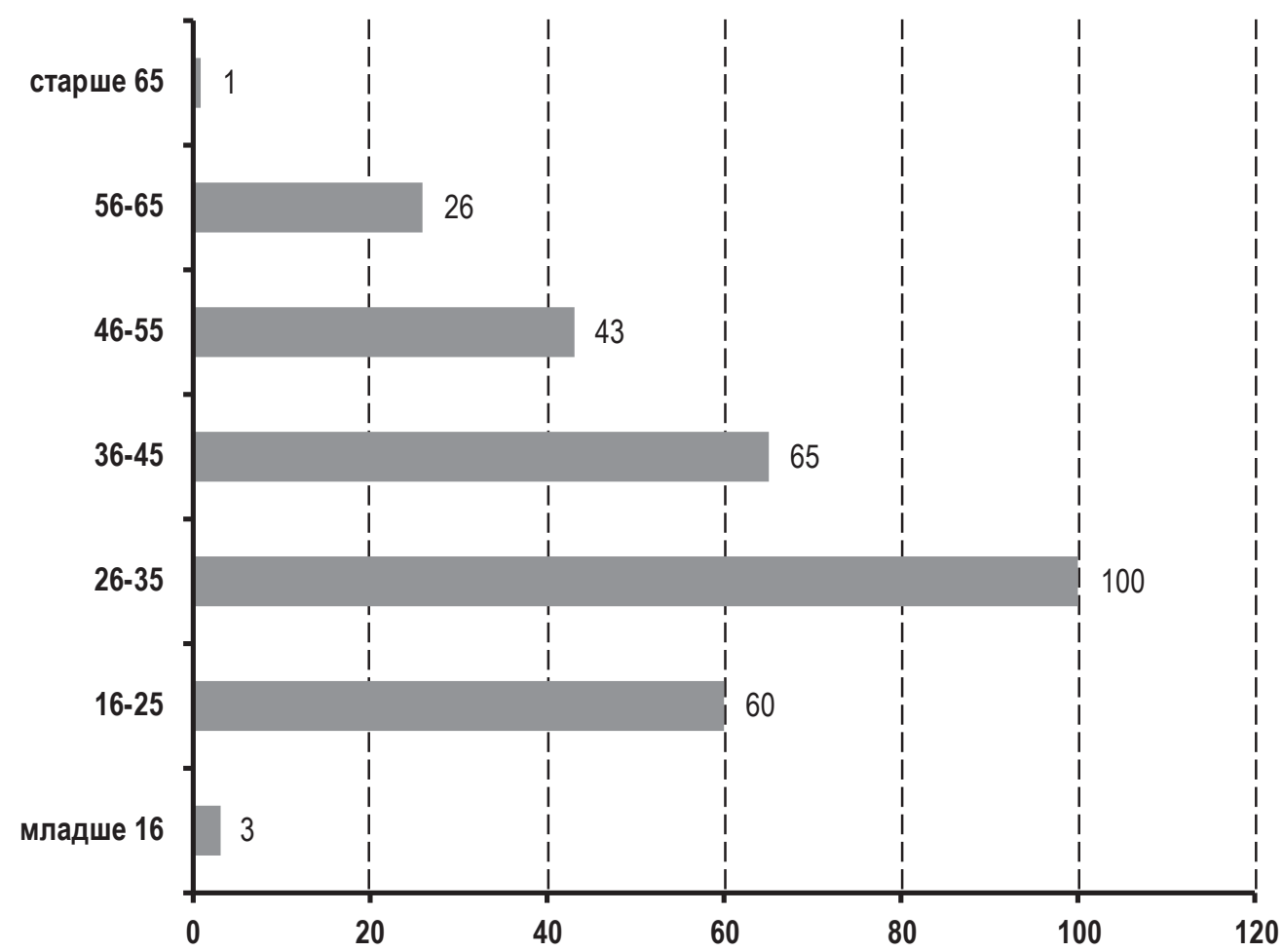

Puc. 3.

Возраст авторов сообщений о митинге 26.03.2017. Источник: составлено автором. пределы столиц и стали общенациональными. Митинги проходили сразу во многих регионах страны, а организованы, инициированы и спровоцированы были всего одной оппозиционной командой - командой Алексея Навального.

Таким образом, использование системы «IQBuzz» позволило создать достаточно полную картину сетевой реакции на сначала анонсированную, затем произошедшую акцию.

Подводя итоги исследования, отметим, что митинг 26 марта 2017 г. был не столь массовым, как в 2005 и 2011-2012 гг., поэтому нельзя считать мартовские события серьёзной угрозой политической системе. Однако методы маргинализации протеста, безотказно работающие с 2011 года, дали обратный эффект.

Команда Навального нашла способ вырваться из медийных оков, в которые его загнала невозможность попасть в телевизор. Навальный стал первым политическим деятелем, которому в новейшей истории России удалось активизировать аполитичную по своей сути молодёжь.

Проведение митингов вызвало резкую негативную реакцию у представителей власти. Так Виталий Милонов, автор многих резонансных законопроектов, предложил запретить использование социальных сетей детям до 14 лет, а также ограничить доступ и ввести «единые правила пользования социальными сетями» для всех остальных категорий граждан. Несмотря на то, что Государственная Дума не приняла этот законопроект к рассмотрению, мы можем говорить о запуске системы «окна Овертона» - благодаря реакции 


\begin{tabular}{|l|c|}
\hline \multicolumn{1}{|c|}{ Регион } & Авторов \\
\hline Москва & 878 \\
\hline Санкт-Петербург & 358 \\
\hline Свердловская область & 146 \\
\hline Краснодарский край & 88 \\
\hline Московская область & 83 \\
\hline Ростовская область & 65 \\
\hline Новосибирская область & 61 \\
\hline Челябинская область & 53 \\
\hline Республика Татарстан & 47 \\
\hline
\end{tabular}

властей обсуждение вреда социальных сетей набирает обороты и в дальнейшем может привести к массовому осуждению использования соцсетей (или всего интернета). Уже сегодня мы можем наблюдать попытки борьбы с интернетом, такие как блокировка «Телеграмм», «Пакет Яровой» и т. д. Такими темпами в России постепенно может сложиться система, схожая с «великим китайским фаерволлом». Об опасности контроля за интернетом со стороны государства не приходится говорить - ведь это последнее место, где оппозиция ещё может открыто выражать свою точку зрения по любым важным вопросам, а социальные сети сегодня - один из самых важных элементов сохранения и функционирования гражданского общества. Таким образом, совершенно очевидно, что власть будет стремиться подчинить своей воле интернет-аудиторию с помощью «мягкой силы» (собственного присутствия в интернет-пространстве и борьбы с оппозицией её методами на её же поле) либо, что более вероятно, с помощью всё того же жёсткого контроля. Второй, гораздо более мягкий и приемлемый вариант - заполнение сетевого пространства контентом лояльных к существующей власти политических акторов, «конвертирующих» своих интернет-сторонников в реальные голоса на выборах. Сегодня мы не можем говорить об активном сопротивлении населения против складывающейся ситуации вокруг сети Интернет. Возможно, это связано с неверием в возможность заблокировать Интернет как таковой (попытка блокировки «Телеграмм») или с представлением о возможности альтернативных путей решения вопроса об анонимности (Уход в «Darknet»).
Табл. 2.

Территориальное распределение сетевой активности участников митинга. Источник: составлено автором. 


\section{Литература}

1. Белл Д. Социальные рамки информационного общества // Новая технократическая волна на Западе. - М.: Прогресс, 1986. С. 330-342.

2. Ильин А. А. Интернет-реальность как социальная актуальная и виртуальная реальности // Социальная политика и социология. 2009. № 2. С. 304-310.

3. Каждому возрасту - свои сети [Электронный документ] // ВЦИОМ. Пресс выпуск. URL: https://wciom.ru/index. php?id=236\&uid=116691 (Дата посещения: 2.10.2018).

4. Карпова А. Ю. Информационная аномия в политической коммуникации. Автореф. ... доктора социол. наук. - М., 2017 [Электронный документ]. URL: https://mgimo.ru/upload/diss/2017/ avtoreferat-karpova-au.pdf (Дата обращения: 19.01.2017).

5. Кремль на развилке: каковы последствия протестных акций по всей России / Е. Кузнецова, В. Дергачёв, А. Гаврилко-Алексеев [Электронный документ] // Ежедневная деловая газета PБК. URL: https://www.rbc.ru/politics/26/03/2017/58d 7c6f39a7947448a1a3f45 (Дата посещения:
11.11.2018).

6. Масуда И. Информационное общество как постиндустриальное общество. М., 1997.587 с.

7. Он вам не Димон. [Электронный документ] // Канал Yotube. URL: https://www. youtube.com/watch?v=qrwlk7_GF9g (Дата посещения: 11.10.2018).

8. Ореханов С. Политизация мема. Как изменилась роль соцсетей в российской политике [Электронный документ] // Московский центр Карнеги. URL: https:// carnegie.ru/commentary/68620 (Дата посещения: 11.10.2018).

9. Павлютенкова М. Ю. Информационно-коммуникационные технологи создания политической медиареальности в России / М. Ю. Павлютенкова, Е. А. Маркова // Проблемы постсоветского пространства. 2017. № 2. С. 137-147.

10. Система мониторинга социальных медиа и СМИ «IQBuzz» [Электронный документ]. URL: http://iqbuzz.pro/ (дата обращения: 11.04.2017).

11. Тоффлер Э. Третья волна. - М.: ACT. 2002. 784 c.

\section{Marina S. TANTSURA}

Ph. D. (in Political Science), Associate Professor, Department of Political Sciences, Oriental Institute - School of Regional and International Studies, Far Eastern Federal University (Vladivostok, Russia)

E-mail: tatuika@mail.ru

\section{Aleksandra A. SADOVNIKOVA}

Master Student, Moscow State University (Moscow, Russia)

E-mail: sandraanna482@gmail.com

\section{Study of Network Activity as an Instrument of Political Mobilization of Youth (on the Example of Anti-Corruption Rallies on March 26, 2017)}

UDC 323.2

doi: dx.doi.org/10.24866/2542-1611/2019-1/46-55 
The problem of network activity of youth has become particularly Internet, relevant in recent years, when the space of Russian politics has Internet technologies, acquired stable virtual characteristics. The practice of mobilizing political participation, young people, bringing them out of the virtual space to offline is a fairly new phenomenon for Russian politics that requires close attention. The paper reflects the results of quantitative and qualitative analysis of the content of social networks in the period network activity, from 02.03.2017 to 15.04.2017 using the social media monitoring rally. program "IQBuzz". The obtained data allowed drawing conclusions about some features of the Russian network communication space. The use of the IQBuzz system allowed us to create a complete picture of the network reaction of political protest. The authors also consider the state reaction to network protest activity.

For citation: Tantsura M. S., Sadovnikova A. A. Study of network activity as an instrument of political mobilization of youth (on the example of anti-corruption rallies on March 26, 2017) // Oriental Institute Journal. 2019. № 1. P. 46-55. doi: dx.doi.org/10.24866/2542-1611/2019-1/46-55

\section{References}

1. Bell D. Sotsial'nye ramki informatsionnogo obshhestva // Novaya tekhnokraticheskaya volna na Zapade. - M.: Progress, 1986. S. 330-342.

2. Il'in A. A. Internet-real'nost' kak sotsial'naya aktual'naya i virtual'naya real'nosti // Sotsial'naya politika i sotsiologiya. 2009. № 2. S. 304-310.

3. Kazhdomu vozrastu - svoi seti [EHlektronnyj dokument] // VTSIOM. Press vypusk. URL: https://wciom.ru/index. php?id=236\&uid=116691 (Data poseshheniya: 2.10.2018).

4. Karpova A. YU. Informatsionnaya anomiya $\mathrm{v}$ politicheskoj kommunikatsii. Avtoref. ... doktora sotsiol. nauk. - M., 2017 [EHlektronnyj dokument]. URL: https:// mgimo.ru/upload/diss/2017/avtoreferatkarpova-au.pdf (Data obrashheniya: 19.01.2017).

5. Kreml' na razvilke: kakovy posledstviya protestnykh aktsij po vsej Rossii / E. Kuznetsova, V. Dergachyov, A. Gavrilko-Alekseev [EHlektronnyj dokument] // Ezhednevnaya delovaya gazeta RBK. URL: https://www.rbc. ru/politics/26/03/2017/58d7c6f39a7947448a1a 3f45 (Data poseshheniya: 11.11.2018).

6. Masuda I. Informatsionnoe obshhestvo kak postindustrial'noe obshhestvo. - M., 1997. $587 \mathrm{~s}$.

7. On vam ne Dimon. [EHlektronnyj dokument] // Kanal Yotube. URL: https://www. youtube.com/watch?v=qrwlk7_GF9g (Data poseshheniya: 11.10.2018).

8. Orekhanov S. Politizatsiya mema. Kak izmenilas' rol' sotssetej $\mathrm{v}$ rossijskoj politike [EHlektronnyj dokument] // Moskovskij tsentr Karnegi. URL: https://carnegie.ru/ commentary/68620 (Data poseshheniya: 11.10.2018).

9. Pavlyutenkova M. YU. Informatsionnokommunikatsionnye tekhnologi sozdaniya politicheskoj mediareal'nosti v Rossii / M. YU. Pavlyutenkova, E. A. Markova // Problemy postsovetskogo prostranstva. 2017. № 2. S. 137-147.

10. Sistema monitoringa sotsial'nykh media i SMI «IQBuzZ» [EHlektronnyj dokument]. URL: http://iqbuzz.pro/ (data obrashheniya: 11.04.2017).

11. Toffler EH. Tret'ya volna. - M.: ACT. 2002. $784 \mathrm{~s}$. 